\title{
Experimental Study on the Escape Velocity of Miners during Mine Fire Periods
}

\author{
Zhang Ruixin,, ${ }^{1,2}$ Nie Rongshan ${ }^{D}{ }^{1}{ }^{1}$ Zhao Hongze ${ }^{(D)},{ }^{1}$ and Fan Yanqiang ${ }^{1}$ \\ ${ }^{1}$ College of Resource and Safety Engineering, China University of Mining and Technology, Beijing 100083, China \\ ${ }^{2}$ North China Institute of Science and Technology, Langfang 065201, China \\ Correspondence should be addressed to Nie Rongshan; nierongshan@126.com
}

Received 19 October 2017; Revised 13 May 2018; Accepted 27 May 2018; Published 27 June 2018

Academic Editor: Francesca Vipiana

Copyright (c) 2018 Zhang Ruixin et al. This is an open access article distributed under the Creative Commons Attribution License, which permits unrestricted use, distribution, and reproduction in any medium, provided the original work is properly cited.

\begin{abstract}
The purpose of this study is to accurately calculate the escape velocity of miners under different roadway conditions during mine fire periods. The experiment to examine escape velocity was carried out in the roadway of the Mu Chengjian Coal Mine. In the experiment, the relationships between the miner escape velocity and the inclination of the roadway, the area of the accessible section of the roadway, and the average wind velocity of the roadway were obtained through single factor analysis, and two multiple regression equations of the escape velocity were developed through multivariable linear regression analysis. The escape velocities of the miners were then predicted, and the error was analyzed with multiple regression equations. The experimental results show that the miner escape velocity decreases with an increase in the absolute value of the inclination of the roadway and increases with an increase of the accessible section area of the roadway and the average wind velocity of the roadway. In addition, the multiple regression equations have the strongest significance if the independent variables are the inclination of the roadway, the accessible section area of the roadway, and the type of roadway, and the contribution rate of the inclination of the roadway to the escape velocity is the highest. The predicted results calculated by the multiple regression equations are close to the experimental data, and the prediction errors are less than $10 \%$. Consequently, we conclude that the multiple regression equations can be used to predict the miner escape velocity during periods of mine fires.
\end{abstract}

\section{Introduction}

Mine fires are very serious issues all over the world [1], and they are a major potential hazard in coal mine production safety [2]. Mine fires are sudden, develop rapidly, are difficult to extinguish, and produce a large number of toxic and harmful gases and heat. After gas and heat production, the fire wind pressure is formed, and it is easy to create disorder in the airflow state and to confuse the entire ventilation system because of the dynamic forces of fire. This may also cause gas or coal dust explosions and can even cause mass death and casualty if the fire is serious; moreover, the mine may suffer irreparable damage and harm [3]. Therefore, it is of great significance to ensure the safety of the miners through developing an escape route for use during a mine fire period [4]. However, choosing the optimal escape route is always a difficult task. Often, heavy casualties and huge economic losses are primarily caused by choosing the wrong escape route in domestic and international fire emergencies.

Recently, domestic and foreign scholars have used computers to examine methods to create an optimal route [57]. At present, studies on the calculation of the escape route are primarily focused on the optimization of computer algorithms, including Yan guangwei et al. [8] who put forward a new method of escape route planning in coal mines by using the improved ant colony algorithm. Gao Rui et al. [9] established a mathematical model of a dynamic rescue route during mine fire periods, solved the model using the improved the algorithm of Dijkstra, and fitted the relation function between the passage time and the temperature. Bai Lele [10] and Yu Dandan [11] have established a model of mine fire evacuation based on the theory of cellular automata. For the existing software of fire emergency rescue, the miner escape velocity is calculated using the coefficient of passage 
difficulty in the roadway as part of the calculation of the optimal escape route $[12,13]$, where the equivalent length of the roadway is obtained by the coefficient of passage difficulty in the roadway multiplied with the actual length of the roadway, and the shortest route is the shortest route of equivalent length $[14,15]$, and some scholars use the passage efficiency to solve the optimal escape route [16]. However, studies about the miner escape velocities have not seriously considered other variables, including the various types of roadways, the accessible section areas of the roadway, the inclinations of the roadway, and the average wind velocities of the roadway during mine fire period, which leads to large errors in the results of the optimal route found by computers. Zhang S et al. [17] obtained a mathematical model of the escape velocity of a roadway through statistical methods, but the model is only applicable to one roadway and cannot be applied to other roadways. Therefore, we carried out a large number of field experiments in various types of roadways. In these experiments, we measured the miner escape velocity and obtained mathematical models of the escape velocity through multiple regression analysis of the experimental data.

\section{Experimental Calculation of Escape Velocity}

2.1. Experiment Introduction. Generally, the main factors that affect the escape velocity of a miner during a mine fire period include the environment of the evacuation route, the personal health status of the miner, the experience of the escape, the level of education and training, the psychological health of the miner, and so on [17]. The environment of the escape route mainly refers to the type of roadway in the escape route, which includes whether the roadway has track or is trackless, the accessible section area of the roadway, the average wind velocity of the roadway, and the inclination of the roadway. Personal health is related to gender, age, exercise ability, and response ability. The health status of the miner is constant in this study because the miner needs to be in good physical health for the heavy work in an underground coal mine. Escape experience is related to whether or not an escape maneuver has been carried out. Education level is related to the degree of education and the individual's understanding of the fire and the escape methods. Psychological health is related to the degree of panic in the face of fire and the adaptability of the miner. In terms of the special environment of a coal mine, almost all coal miners have received vocational training and often complete corresponding disaster rescue exercises, such that escape experience, education, and psychological quality are also considered to be the same in this study. In general, the factors that affect the escape velocity of a miner during a mine fire period are the type of roadway $X_{1}$, the accessible section area of the roadway $X_{2}$, the inclination of the roadway $X_{3}$, and the average wind velocity of the roadway $X_{4}$.

Above all, the escape velocity of a miner was measured in different types of roadway and with different accessible section areas, inclinations, and average wind velocities of the roadway in the experiment. The mathematical models of the miner escape velocity were obtained in any roadway, where the inclined roadway includes uphill and downhill, and the average wind velocity includes passing downwind and upwind. To simplify the factors that affect the escape velocity, the participants that passed through the uphill and downhill in the inclined roadway were expressed by a positive number and a negative number, respectively, and the average wind velocity of the miner passing downwind and upwind was expressed in the experiment by a positive and negative number, respectively. In addition, the selected experimental mine must have all kinds of complicated and inclined roadways in the experiment. Based on the above reasons, the $\mathrm{Mu}$ Chengjian Coal Mine owned by the Beijing Haohua Energy Co., Ltd., was selected as the experimental mine, and it has multiple levels of exploitation. There are several inlet air inclined shafts and return air inclined shafts that connect each production level, and the inclinations of the roadway are different in the coal mine, so that it is an ideal mine for this experiment on the escape velocity.

\subsection{Experimental Equipment and Participants. The passage} time of the miner in the roadway was recorded by a stopwatch in the experiment. The inclination of the roadway was measured by a plumb level, and the average wind velocity of the roadway was measured by an air-flow meter. Compared with participants who have had no work experience with participants who have rich experience in the underground coal mine, there is a great difference in the escape velocity, and thus ten miners were selected as the experimental participants. In addition, the participants were in good health, without heart disease, and were normotensive with rich experience in underground coal mines. The average age and average age of employment of the miners selected for this experiment was 38 years and 12.6 years, respectively. Therefore, all of the participants involved in the experiment have had rich working experiences in coal mine production and were familiar with the condition of the coal mine and the layout of the roadway. The miners participating in the experiment were equipped with miner clothing, boots, helmets, a miner's lamp, a self-rescuer, and a GPS locator.

2.3. Experimental Scheme. In this paper, the following steps were taken to carry out the experiment on escape velocity. First, a roadway was selected, and the length was measured. If the roadway was horizontal, the measuring length was two hundred meters; otherwise, the measuring length was one hundred meters. To intuitively analyze the influence of various factors on the miner escape velocity, it was necessary to select various roadways with significant differences in the inclination of the roadway, the average wind speed of the roadway, and the accessible section area of the roadway. In addition, to avoid having the accessible section area of the roadway and the average wind velocity of the roadway changed significantly in each test, the roadway with the smallest change of accessible section area and no branch should be selected each time as much as possible when choosing the test roadway.

Second, the inclination of the roadway was measured by a plumb level, the width and height of the roadway were 


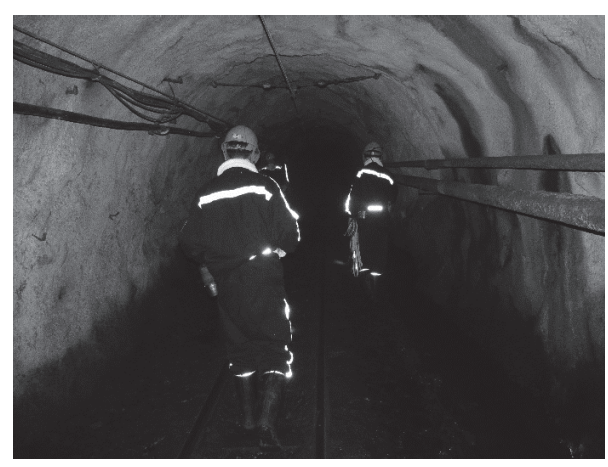

FIGURE 1: Escape experiment in a horizontal roadway.

measured by a steel tape, and the roadway shape was recorded at the same time. Thus, the accessible section area of the roadway can be calculated. To make the data more accurate, the height and width of the roadway were measured every fifty meters from the starting position to the end position, and the final height and width of the roadway were obtained by calculating the average of the measured data.

Third, the average wind velocity of the roadway was measured by with a mechanical air flow meter, and the snake-route method was used for the measurement of the wind average velocity. Furthermore, the wind velocity was measured three times in each test position, and the average of three measurements was calculated. Moreover, the average wind velocity was measured every fifty meters from the starting position to the end position, and the final average wind velocity was obtained by calculating the average of the measured data.

Finally, the participants wore a stopwatch in the experiment, which was started when the escape experiment was carried out each time, and the passage time of each participant was recorded at the end of the test. To ensure the accuracy of the experimental results, the participants carried out the escape experiment each time at 30-s intervals, taking into account that the space of roadway was small and crowded, which does not allow ten participants to escape at the same time. In addition, the round-trip passage times of the miner were tested twice in the same test roadway to study the effect of the average wind velocity of the roadway and the effect of whether the incline was uphill and downhill in the inclined roadway on the miner escape velocity. The experiments of escape velocity were carried out in horizontal and inclined roadways as shown in Figures 1 and 2, respectively.

\section{Results and Statistical Analyses}

Table 1 shows the eighty groups of experimental data that were obtained through the experiment on the escape velocity of miners in the horizontal roadway and the inclined roadway of the Mu Chengjian Coal Mine during a mine fire period. In addition, the escape velocity at each test was calculated by formula (1), where $Y_{i}$ is the escape velocity for each miner and $\bar{Y}$ is the average escape velocity for ten participants:

$$
E(\bar{Y})=\frac{1}{10} \sum_{i=1}^{10} Y_{i}
$$

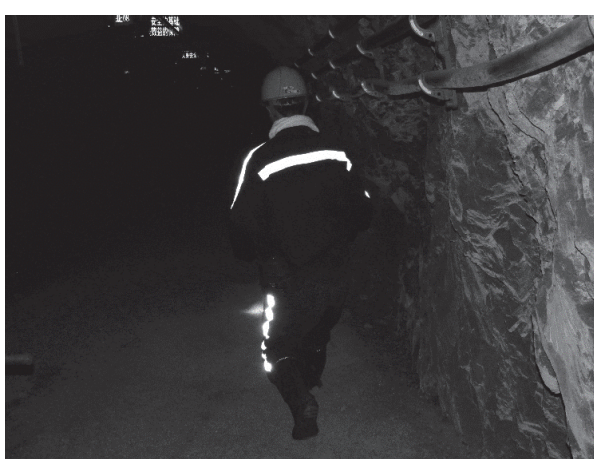

FIGURE 2: Escape experiment in an inclined roadway.

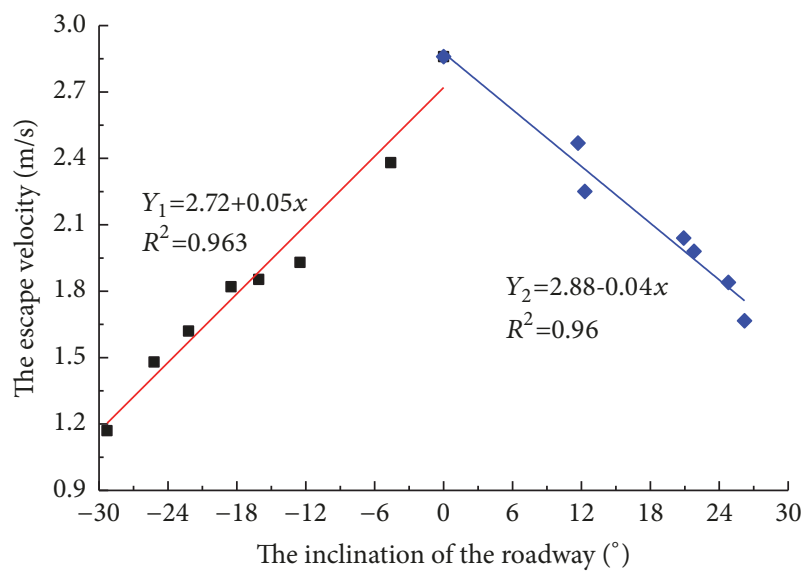

FIGURE 3: The relationship between the miner escape velocity and the inclination of the roadway.

3.1. Single Factor Analysis. The effect of single factors on the miner escape velocities during the mine fire period was analyzed to study the coupling relationship between the miner escape velocity and the type of roadway, the accessible section area of the roadway, the inclination of the roadway, and the average wind velocity of the roadway. In addition, the type of roadway was not analyzed since the type of roadway was only divided into track roadway and trackless roadway. In this way, the method used for multifactor coupling analysis can be determined through the corresponding relationship between the miner escape velocity and each factor.

3.1.1. The Influence of the Inclination of the Roadway on the Miner Escape Velocities. To study the influence of the inclination of the roadway on the miner escape velocity during the mine fire period experiment, we selected the fifteen groups of the experimental data that included the inclination of the roadway with the largest differences and had an average wind velocity of the roadway between $1 \mathrm{~m} / \mathrm{s}$ and $3 \mathrm{~m} / \mathrm{s}$ and had an accessible section area of the roadway between $6 \mathrm{~m}^{2}$ and $11 \mathrm{~m}^{2}$. The trackless roadways were selected for comparative analysis by the control variable method, and then the influence laws of the inclination of the roadway on the miner escape velocity were obtained using the origin software, as shown in Figure 3. As seen in Figure 3, the miner 
TABLE 1: Experimental data of escape velocity.

\begin{tabular}{|c|c|c|c|c|c|c|}
\hline No. & Roadway name & Roadway type & $\begin{array}{l}\text { Roadway section area } \\
\left(\mathrm{m}^{2}\right)\end{array}$ & $\begin{array}{c}\text { inclination } \\
\left({ }^{\circ}\right)\end{array}$ & $\begin{array}{l}\text { wind velocity } \\
(\mathrm{m} / \mathrm{s})\end{array}$ & $\begin{array}{l}\text { Escape velocity } \\
(\mathrm{m} / \mathrm{s})\end{array}$ \\
\hline 1 & +250 west roadway- +450 ventilation slope & Without rail track & 6.18 & -29.3 & 2.17 & 1.17 \\
\hline 2 & $+450-+570$ first ventilation slope & Without rail track & 6.78 & -28.5 & -2.89 & 1.24 \\
\hline 3 & $+820-+930$ return air slope & Without rail track & 8.53 & -28.3 & 8.69 & 1.28 \\
\hline 4 & $+450-+570$ air shaft & Without rail track & 6.96 & -27.5 & -3.16 & 1.28 \\
\hline 5 & $+250-+450$ inclined shaft & Without rail track & 14.35 & -27.5 & -0.82 & 1.39 \\
\hline 6 & +450 haulage roadway & Rail track & 12.85 & -26.8 & 1.72 & 1.34 \\
\hline 7 & $+150-+250$ ventilation slope & Without rail track & 8.77 & -26.6 & -3.39 & 1.32 \\
\hline 8 & $+150-+250$ impractical person vehicle slope & Without rail track & 10.87 & -26.2 & -1.02 & 1.45 \\
\hline 9 & $+450-+570$ second ventilation slope & Without rail track & 8.24 & -25.2 & 1.42 & 1.48 \\
\hline 10 & +570 -+700 first ventilation slope & Without rail track & 9.28 & -24.8 & -2.64 & 1.53 \\
\hline 11 & $+700-+820$ ventilation slope & Without rail track & 7.81 & -24.6 & 3.25 & 1.56 \\
\hline 12 & $+450-+570$ impractical person vehicle slope & Without rail track & 12.89 & -23.3 & -2.17 & 1.58 \\
\hline 13 & $+570-+700$ second ventilation slope & Without rail track & 9.23 & -22.2 & 1.54 & 1.62 \\
\hline 14 & +570 uphill slope & Without rail track & 6.60 & -21.8 & -0.94 & 1.69 \\
\hline 15 & $+150-+250$ overhead cableway & Without rail track & 14.17 & -21.5 & -2.28 & 1.68 \\
\hline 16 & +250 belt roadway -+450 ventilation slope & Without rail track & 9.23 & -20.9 & -2.29 & 1.71 \\
\hline 17 & $+450-+570$ coal flume slope & Rail track & 1.89 & -20.3 & 1.23 & 0.68 \\
\hline 18 & $+150-+250$ auxiliary shaft slope & Without rail track & 8.13 & -19.8 & -3.46 & 1.77 \\
\hline 19 & +150 air shaft & Without rail track & 7.91 & -18.5 & 1.12 & 1.82 \\
\hline 20 & $+250-+450$ belt main inclined shaft & Without rail track & 6.87 & -15.6 & -3.23 & 1.92 \\
\hline 21 & $+570-+700$ belt slope & Without rail track & 7.38 & -12.3 & 1.86 & 1.93 \\
\hline 22 & +250 down crossheading of third face & Without rail track & 5.95 & -11.7 & -1.83 & 2.30 \\
\hline 23 & +450 down crossheading of fifth face & Without rail track & 7.24 & -8.6 & -0.83 & 2.32 \\
\hline 24 & +450 up crossheading of fifth face & Without rail track & 9.47 & -6.4 & 0.68 & 2.35 \\
\hline 25 & +250 up crossheading of third face & Without rail track & 9.36 & -4.6 & 2.13 & 2.38 \\
\hline 26 & +450 up crossheading of first face & Without rail track & 4.83 & -4.2 & -0.74 & 1.92 \\
\hline 27 & +820 haulage roadway & Rail track & 14.35 & 0 & 1.48 & 3.35 \\
\hline 28 & +820 haulage roadway & Rail track & 14.35 & 0 & -1.48 & 2.47 \\
\hline 29 & +700 belt roadway & Without rail track & 6.34 & 0 & 1.58 & 2.86 \\
\hline 30 & +700 belt roadway & Without rail track & 6.34 & 0 & -1.58 & 2.73 \\
\hline 31 & +570 haulage roadway & Rail track & 13.85 & 0 & 1.78 & 3.41 \\
\hline 32 & +570 haulage roadway & Rail track & 13.85 & 0 & -1.78 & 2.41 \\
\hline 33 & +250 bottom road of second east cross drift & Rail track & 13.11 & 0 & -0.42 & 2.94 \\
\hline 34 & +250 bottom road of second east cross drift & Rail track & 13.11 & 0 & 0.42 & 3.08 \\
\hline 35 & +250 haulage roadway & Rail track & 6.61 & 0 & 1.12 & 2.83 \\
\hline 36 & +250 haulage roadway & Rail track & 6.61 & 0 & -1.12 & 2.67 \\
\hline 37 & +450 up crossheading of first face & Without rail track & 4.83 & 4.2 & 0.74 & 2.04 \\
\hline 38 & +250 up crossheading of third face & Without rail track & 9.36 & 4.6 & -2.13 & 2.60 \\
\hline 39 & +450 up crossheading of fifth face & Without rail track & 9.47 & 6.4 & -0.68 & 2.57 \\
\hline 40 & +450 down crossheading of fifth face & Without rail track & 7.24 & 8.6 & 0.83 & 2.54 \\
\hline 41 & +250 down crossheading of third face & Without rail track & 5.95 & 11.7 & 1.83 & 2.47 \\
\hline 42 & $+570-+700$ belt slope & Without rail track & 7.38 & 12.3 & -1.86 & 2.38 \\
\hline 43 & $+250-+450$ belt main inclined shaft & Without rail track & 6.87 & 15.6 & 3.23 & 2.19 \\
\hline 44 & +150 air shaft & Without rail track & 7.91 & 18.5 & -1.12 & 2.11 \\
\hline 45 & $+150-+250$ auxiliary shaft slope & Without rail track & 8.13 & 19.8 & 3.46 & 2.07 \\
\hline 46 & $+450-+570$ coal flume slope & Rail track & 1.89 & 20.3 & -1.23 & 0.76 \\
\hline 47 & +250 belt roadway -+450 ventilation slope & Without rail track & 9.23 & 20.9 & 2.29 & 2.04 \\
\hline
\end{tabular}


TABLE 1: Continued.

\begin{tabular}{|c|c|c|c|c|c|c|}
\hline No. & Roadway name & Roadway type & $\begin{array}{l}\text { Roadway section area } \\
\left(\mathrm{m}^{2}\right)\end{array}$ & $\begin{array}{c}\text { inclination } \\
\left(^{\circ}\right)\end{array}$ & $\begin{array}{l}\text { wind velocity } \\
(\mathrm{m} / \mathrm{s})\end{array}$ & $\begin{array}{l}\text { Escape velocity } \\
(\mathrm{m} / \mathrm{s})\end{array}$ \\
\hline 48 & $+150-+250$ overhead cableway & Without rail track & 14.17 & 21.5 & 2.28 & 2.01 \\
\hline 49 & +570 uphill slope & Without rail track & 6.60 & 21.8 & 0.94 & 1.98 \\
\hline 50 & $+570-+700$ second ventilation slope & Without rail track & 9.23 & 22.2 & -1.54 & 1.95 \\
\hline 51 & $+450-+570$ impractical person vehicle slope & Without rail track & 12.89 & 23.3 & 2.17 & 1.89 \\
\hline 52 & $+700-+820$ ventilation slope & Without rail track & 7.81 & 24.6 & -3.25 & 1.71 \\
\hline 53 & +570 -+700 first ventilation slope & Without rail track & 9.28 & 24.8 & 2.64 & 1.84 \\
\hline 54 & $+450-+570$ second ventilation slope & Without rail track & 8.24 & 25.2 & -1.42 & 1.78 \\
\hline 55 & $+150-+250$ impractical person vehicle slope & Without rail track & 10.87 & 26.2 & 1.02 & 1.67 \\
\hline 56 & $+150-+250$ ventilation slope & Without rail track & 8.77 & 26.6 & 3.39 & 1.38 \\
\hline 57 & +450 drawing roadway & Rail track & 12.85 & 26.8 & 1.72 & 1.55 \\
\hline 58 & $+450-+570$ air shaft & Without rail track & 6.96 & 27.5 & 3.16 & 1.34 \\
\hline 59 & +820-+930 return air slope & Without rail track & 8.53 & 28.3 & -8.69 & 0.98 \\
\hline 60 & $+450-+570$ first ventilation slope & Without rail track & 6.78 & 28.5 & 2.89 & 1.28 \\
\hline 61 & $+250-+450$ ventilation slope & Without rail track & 6.18 & 29.3 & -2.17 & 1.22 \\
\hline 62 & $+250-+450$ auxiliary shaft slope & Without rail track & 14.35 & 27.5 & 0.82 & 1.64 \\
\hline 63 & +820 fifth west cross drift & Rail track & 12.83 & 0 & 2.31 & 2.86 \\
\hline 64 & +820 fifth west cross drift & Rail track & 12.83 & 0 & -2.31 & 2.79 \\
\hline 65 & +820 roof road of north cross drift & Rail track & 13.14 & 0 & 2.04 & 2.82 \\
\hline 66 & +820 roof road of north cross drift & Rail track & 13.14 & 0 & -2.04 & 2.76 \\
\hline 67 & +570 seventh west cross drift & Rail track & 9.36 & 0 & 2.31 & 2.64 \\
\hline 68 & +570 seventh west cross drift & Rail track & 9.36 & 0 & -2.31 & 2.58 \\
\hline 69 & +150 down crossheading of second face & Without rail track & 7.04 & -16.1 & 1.21 & 1.85 \\
\hline 70 & +150 down crossheading of second face & Without rail track & 7.04 & 16.1 & -1.21 & 2.16 \\
\hline 71 & +150 up crossheading of second face & Without rail track & 9.60 & -12.3 & -1.28 & 2.02 \\
\hline 72 & +150 up crossheading of second face & Without rail track & 9.60 & 12.3 & 1.28 & 2.25 \\
\hline 73 & +150 east level roadway & Rail track & 13.87 & 0 & 1.12 & 2.88 \\
\hline 74 & +150 east level roadway & Rail track & 13.87 & 0 & -1.12 & 2.82 \\
\hline 75 & +150 mining section east roadway & Rail track & 9.83 & 0 & 1.45 & 2.64 \\
\hline 76 & +150 mining section east roadway & Rail track & 9.83 & 0 & -1.45 & 2.67 \\
\hline 77 & +700 second west cross drift & Rail track & 12.17 & 0 & 2.26 & 2.81 \\
\hline 78 & +700 second west cross drift & Rail track & 12.17 & 0 & -2.26 & 2.73 \\
\hline 79 & +450 haulage roadway & Rail track & 10.68 & 0 & 2.17 & 2.74 \\
\hline 80 & +450 haulage roadway & Rail track & 10.68 & 0 & -2.17 & 2.62 \\
\hline
\end{tabular}

escape velocity increases with the inclination of the roadway if the inclination of the roadway is less than zero, and the miner escape velocity decreases with the inclination of the roadway if the inclination of the roadway is greater than or equal to zero. Generally, the miner escape velocity decreases gradually with the increase of the absolute value of the inclination.

3.1.2. The Influence of the Average Wind Velocity on the Miner Escape Velocity. To study the influence of the average wind velocity on the miner escape velocity during the mine fire period experiment, we selected the sixteen groups of experimental data that included the average wind velocity of the roadway with the largest differences and had an inclination of the roadway of zero and an accessible section area of the roadway between $12 \mathrm{~m}^{2}$ and $15 \mathrm{~m}^{2}$. The roadways with tracks were selected for comparative analysis by the control variable method, and then the influence laws of the average wind velocity of the roadway on the miner escape velocity were obtained. The miner escape velocity increases with the average wind velocity of the roadway, as shown in Figure 4.

3.1.3. The Influence of the Accessible Section Area on the Miner Escape Velocity. To study the influence of the inclination of the roadway on the miner escape velocity during the experimental mine fire period, we selected the seven groups of experimental data that included the accessible section area of the roadway with the largest differences, with an 


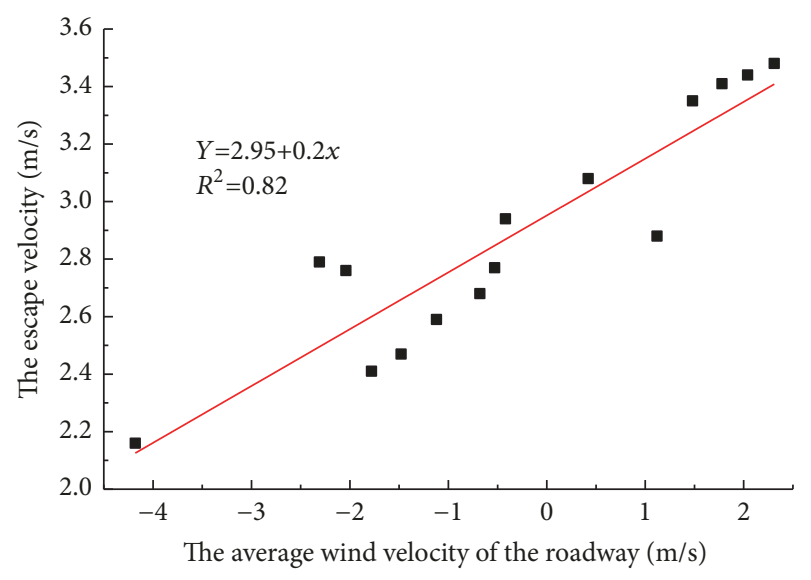

FIgURE 4: The relationship between the miner escape velocity and the average wind velocity.

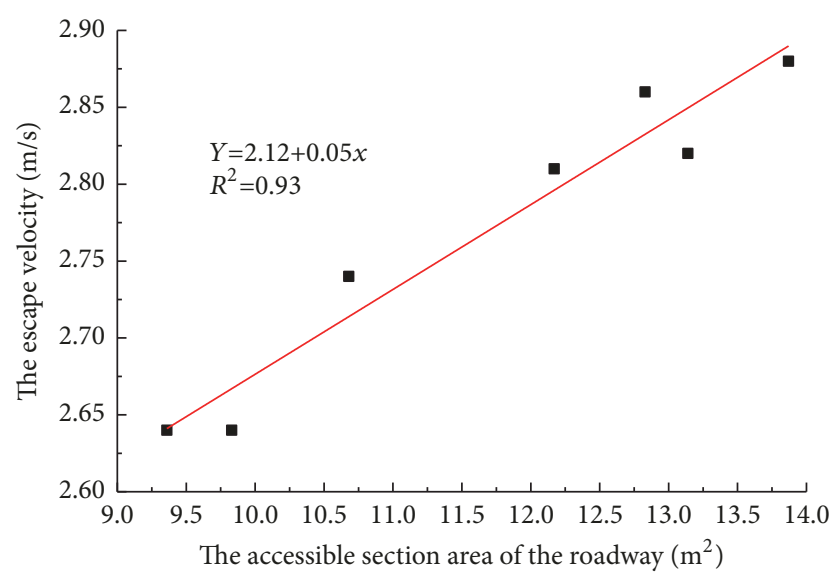

FIGURE 5: The relationship between the miner escape velocity and the accessible section area of the roadway.

inclination of the roadway of zero and an average wind velocity of the roadway between $2 \mathrm{~m} / \mathrm{s}$ and $2.5 \mathrm{~m} / \mathrm{s}$. The withtrack roadways were selected for comparative analysis by the control variable method, and then the influence laws of the accessible section area of the roadway on the miner escape velocity were obtained. The miner escape velocity increases with the accessible section area of the roadway, as shown in Figure 5.

According to the above analysis, the miner escape velocity decreases with the increase of the absolute value of the inclination of the roadway and increases with the increase of the accessible section area of the roadway and the average wind velocity of the roadway. We can therefore conclude that there is a linear relationship between the influence factors and the miner escape velocity. Therefore, we used the method of multiple linear regressions to analyze the effect of multifactor coupling on the miner escape velocity using SPSS statistical analysis software. Multiple regression equations are obtained between the miner escape velocity and the various influencing factors.

\subsection{Multivariable Linear Regression Analysis}

3.2.1. Selection of Independent Variables. To introduce the nonnumerical data into the multivariable linear regression models, the nonnumerical data are introduced into the model in the form of dummy variables, because the type of roadway is a nonnumerical dataset that cannot be processed using the multivariable regression analysis method in the process of analyzing the factors that affect the miner escape velocity. The regression coefficient is estimated and tested in the same way as a quantitative variable if the dummy variable is applied to the model, but its meaning is changed, which reflects the specific effect of a certain category compared with the basic category. Therefore, the type of roadway, which includes the roadway with rail track and without rail track, was expressed as 1 and 2 .

The independent variables were selected using the stepwise regression method which followed the principle of minimizing the number of explanatory variables as much as possible when choosing an independent variable to make the model sufficiently streamlined. The goal of this method is to consider the degree of contribution and significance of each independent variable on the dependent variable and to order them from large to small significant in the regression equation. Those variables that have no significant effect may be left out of the regression equation. In addition, variables that have been introduced into the regression equation may become less important after introducing new variables and need to be removed from the regression equation. The introduction of a variable or exclusion of a variable from the regression equation is a step towards stepwise regression, and each step is carried out to ensure that the regression equation contains only variables that have significant effects before the introduction of the new variable ensure that no significant variables have been removed $[18,19]$.

3.2.2. The Mathematical Model of Multivariate Regression. Multivariate linear regression analysis is a widely applied method of data analysis, and it is established based on the observational data of multiple correlations between variables used to appropriately analyze the inherent laws of data changes, which can be used for prediction and control. The multiple regression methods are needed if the dependent variable is affected by several independent variables [20].

Assuming that the dependent variable $Y$ is linearly related to multiple independent variables $X_{1}, X_{2}, \cdots X_{k}$, it can be described by a multivariate linear function of the independent variable, known as the multiple linear regression model. This is given by

$$
Y=\beta_{0}+\beta_{1} X_{1}+\beta_{2} X_{2}+\cdots+\beta_{k} X_{k}+u
$$

where $Y$ is the dependent variable, $X_{j}(j=1,2, \cdots k)$ is $k$ independent variables, $\beta_{j}(j=0,1,2, \cdots, k)$ is $k$ unknown parameters, and $\mu$ is a random error term.

The linear equation of the expected value of the dependent variable $Y$ and the independent variables $X_{1}, X_{2}, \cdots X_{k}$ is given by

$$
E(Y)=\beta_{0}+\beta_{1} X_{1}+\beta_{2} X_{2}+\cdots+\beta_{k} X_{k}
$$


which is known as the multivariate global linear regression equation, often referred to as the global regression equation.

For the $n$ groups of observation $Y_{i}, X_{1 i}, X_{2 i}, \cdots X_{k i}(i=$ $0,1,2, \cdots, n)$, the form of the equation is

$$
\begin{aligned}
Y_{i}=\beta_{0}+\beta_{1} X_{1 i}+\beta_{2} X_{2 i}+\cdots+\beta_{k} X_{k i}+ & u_{i}, \\
& (i=1,2, \cdots n),
\end{aligned}
$$

and the matrix form is

$$
\left[\begin{array}{c}
Y_{1} \\
Y_{2} \\
\vdots \\
Y_{n}
\end{array}\right]=\left[\begin{array}{ccccc}
1 & X_{11} & X_{21} & \cdots & X_{k 1} \\
1 & X_{12} & X_{22} & \cdots & X_{k 2} \\
\vdots & \vdots & \vdots & \ddots & \vdots \\
1 & X_{1 n} & X_{2 n} & \cdots & X_{k n}
\end{array}\right]\left[\begin{array}{c}
\beta_{1} \\
\beta_{2} \\
\vdots \\
\beta_{k}
\end{array}\right]+\left[\begin{array}{c}
\mu_{1} \\
\mu_{2} \\
\vdots \\
\mu_{n}
\end{array}\right] \text {, }
$$

where $Y=X \beta+\mu$ and where

$$
Y_{n \times 1}=\left[\begin{array}{c}
Y_{1} \\
Y_{2} \\
\vdots \\
Y_{n}
\end{array}\right]_{n \times 1}
$$

is the observed vector of the dependent variable,

$$
X_{n \times(k+1)}=\left[\begin{array}{ccccc}
1 & X_{11} & X_{21} & \cdots & X_{k 1} \\
1 & X_{12} & X_{22} & \cdots & X_{k 2} \\
\vdots & \vdots & \vdots & \ddots & \vdots \\
1 & X_{1 n} & X_{2 n} & \cdots & X_{k n}
\end{array}\right]
$$

is the observation matrix of the independent variables,

$$
\beta_{(k+1) \times 1=}\left[\begin{array}{c}
\beta_{1} \\
\beta_{2} \\
\vdots \\
\beta_{k}
\end{array}\right]
$$

is the global regression parameter vector, and

$$
\mu_{n \times 1}=\left[\begin{array}{c}
\mu_{1} \\
\mu_{2} \\
\vdots \\
\mu_{n}
\end{array}\right]
$$

is a random error vector.

The global regression equation is expressed as

$$
E(Y)=X \beta .
$$

The parameters can be estimated by the sample observations $\left(X_{1}, X_{2}, \ldots, X_{k i} ; Y_{i}\right)$ because the parameters $\beta_{0}, \beta_{1}, \ldots \beta_{k}$ are unknown.
If the calculated parameters $\widehat{\beta}_{0}, \widehat{\beta}_{1}, \widehat{\beta}_{2}, \cdots, \widehat{\beta}_{k}$ are used to replace the unknown parameters $\beta_{0}, \beta_{1}, \ldots, \beta_{k}$ of the global regression function, the regression equation of the multivariate linear sample is

$$
\widehat{Y}_{i}=\widehat{\beta}_{0}+\widehat{\beta}_{1} X_{1 i}+\widehat{\beta}_{2 i}+\cdots+\widehat{\beta}_{k i} X_{k i},
$$

where $\widehat{\beta}_{j}(j=0,1,2, \cdots, k)$ is the parameter estimate and $\widehat{Y}_{i}(i=1,2, \cdots, n)$ is the sample regression value or the sample fitting value with a sample estimate value of $Y_{i}$.

The form of the matrix expression is

$$
\widehat{Y}=X \widehat{\beta},
$$

where

$$
\widehat{Y}_{n \times 1}=\left[\begin{array}{c}
\widehat{Y}_{1} \\
\widehat{Y}_{2} \\
\vdots \\
\widehat{Y}_{n}
\end{array}\right]
$$

is the $n \times 1$ order fitting vector of the vector $Y$ of the dependent variable,

$$
X_{n \times(k+1)}=\left[\begin{array}{ccccc}
1 & X_{11} & X_{21} & \cdots & X_{k 1} \\
1 & X_{12} & X_{22} & \cdots & X_{k 2} \\
\vdots & \vdots & \vdots & \ddots & \vdots \\
1 & X_{1 n} & X_{2 n} & \cdots & X_{k n}
\end{array}\right]
$$

is the $n \times(k+1)$ order sample observation matrix of the independent variable $X$, and

$$
\widehat{\beta}_{(k+1) \times 1=}\left[\begin{array}{c}
\widehat{\beta}_{0} \\
\widehat{\beta}_{1} \\
\widehat{\beta}_{2} \\
\vdots \\
\widehat{\beta}_{k}
\end{array}\right]
$$

is the $(k+1) \times 1$ order estimate column vector of the unknown parameter vector $\beta$.

The deviation between the observed value $Y_{i}$ obtained from the sample regression equation and the value of the dependent variable estimate $\widehat{Y}_{i}$ becomes the residual $e_{i}$ :

$$
e_{i}=Y_{i}-\widehat{Y}_{i}=Y_{i}-\left(\widehat{\beta}_{0}+\widehat{\beta}_{1} X_{1 i}+\widehat{\beta}_{2 i}+\cdots+\widehat{\beta}_{k i} X_{k i}\right)
$$

3.2.3. The Results of Multivariable Regression Analysis. Through the analysis of the single factor influence, the relationship between the miner escape velocity and the inclination of the roadway is nonlinear. However, if the data of the inclinations of the roadway are divided into two groups (where the inclination of the roadway is less than zero in one group and the inclination of the roadway is greater than or 
TABLE 2: Variables entered/removed from the regression. ${ }^{\mathrm{a}}$

\begin{tabular}{|c|c|c|c|}
\hline Model & Variables Entered & Variables Removed & Method \\
\hline 1 & Inclination & & $\begin{array}{l}\text { Stepwise (Criteria: Probability-of-F-to-enter }<=0.05 \text {, Probability-of-F-to-remove } \\
\qquad>=0.1) .\end{array}$ \\
\hline 2 & Accessible section area & & $\begin{array}{l}\text { Stepwise (Criteria: Probability-of-F-to-enter }<=0.05 \text {, Probability-of-F-to-remove } \\
\qquad>=0.1) .\end{array}$ \\
\hline 3 & Type of the roadway & & $\begin{array}{l}\text { Stepwise (Criteria: Probability-of-F-to-enter }<=0.05 \text {, Probability-of-F-to-remove } \\
\qquad>=0.1) .\end{array}$ \\
\hline 4 & & Average wind velocity & $\begin{array}{l}\text { Stepwise (Criteria: Probability-of-F-to-enter }<=0.05 \text {, Probability-of-F-to-remove } \\
\qquad>=0.1) .\end{array}$ \\
\hline
\end{tabular}

a. Dependent variable: the miner escape velocity.

TABLE 3: Model Summary.

\begin{tabular}{lcccccccc}
\hline \multirow{2}{*}{ Model } & \multicolumn{2}{c}{$\mathrm{R}$} & \multicolumn{2}{c}{ R-Squared } & \multicolumn{2}{c}{ Adjusted R-Squared } & \multicolumn{2}{c}{ Std. Error of the estimate } \\
& Dip $\leqslant 0$ & Dip $\geqslant 0$ & Dip $\leqslant 0$ & Dip $\geqslant 0$ & Dip $\leqslant 0$ & Dip $\geqslant 0$ & Dip $\leqslant 0$ & 0.313 \\
\hline 1 & $0.893^{\mathrm{a}}$ & $0.868^{\mathrm{a}}$ & 0.798 & 0.753 & 0.791 & 0.745 & 0.264 & 0.233 \\
3 & $0.921^{\mathrm{b}}$ & $0.901^{\mathrm{b}}$ & 0.848 & 0.811 & 0.837 & 0.798 & 0.279 & 0.213 \\
\hline
\end{tabular}

a. Predictors: (constant) the inclination of the roadway.

b. Predictors: (constant) the inclination of the roadway and the accessible section area of the roadway.

c. Predictors: (constant) the inclination of the roadway, the accessible section area of the roadway, and the type of roadway.

TABLE 4: ANOVA ${ }^{\mathrm{a}}$.

\begin{tabular}{|c|c|c|c|c|c|c|c|c|c|c|c|}
\hline \multirow{2}{*}{\multicolumn{2}{|c|}{ Model }} & \multicolumn{2}{|c|}{ Sum of Squares } & \multicolumn{2}{|c|}{$\mathrm{df}$} & \multicolumn{2}{|c|}{ Mean Square } & \multicolumn{2}{|c|}{$\mathrm{F}$} & \multicolumn{2}{|c|}{ Sig. } \\
\hline & & Dip $\leqslant 0$ & Dip $\geqslant 0$ & Dip $\leqslant 0$ & Dip $\geqslant 0$ & Dip $\leqslant 0$ & Dip $\geqslant 0$ & Dip $\leqslant 0$ & Dip $\geqslant 0$ & Dip $\leqslant 0$ & Dip $\geqslant 0$ \\
\hline \multirow{3}{*}{1} & Regression & 7.685 & 8.975 & 1 & 1 & 7.685 & 8.975 & 110.520 & 91.541 & $0.000^{\mathrm{b}}$ & $0.000^{\mathrm{b}}$ \\
\hline & Residual & 1.947 & 2.941 & 28 & 30 & 0.070 & 0.098 & & & & \\
\hline & Total & 9.632 & 11.916 & 29 & 31 & & & & & & \\
\hline \multirow{3}{*}{2} & Regression & 8.171 & 9.665 & 2 & 2 & 4.086 & 4.832 & 75.514 & 62.259 & $0.000^{c}$ & $0.000^{c}$ \\
\hline & Residual & 1.461 & 2.251 & 27 & 29 & 0.054 & 0.078 & & & & \\
\hline & Total & 9.632 & 11.916 & 29 & 31 & & & & & & \\
\hline \multirow{3}{*}{3} & Regression & 8.451 & 10.087 & 3 & 3 & 2.817 & 3.362 & 62.018 & 51.473 & $0.000^{\mathrm{d}}$ & $0.000^{\mathrm{d}}$ \\
\hline & Residual & 1.181 & 1.829 & 26 & 28 & 0.045 & 0.065 & & & & \\
\hline & Total & 9.632 & 11.916 & 29 & 31 & & & & & & \\
\hline
\end{tabular}

a. Dependent variable: the miner escape velocity.

b. Predictors: (constant) the inclination of the roadway.

c. Predictors: (constant) the inclination of the roadway and the accessible section area of the roadway.

d. Predictors: (constant) the inclination of the roadway, the accessible section area of the roadway, and the type of roadway.

equal to zero in the other group), there are linear relationships between the escape velocity and the inclination of roadway, the accessible section area of the roadway, and the average wind velocity of the roadway in each group of data. In this way, the data of 1-30 sets in which the inclination of the roadway is less than zero is the first group, and the 31-61 group datasets in which the inclination of the roadway is greater than or equal to zero are the second group of data.

Finally, the two groups of data were analyzed, respectively, using multivariable linear regression analysis. The results of the multivariable linear regression analysis of the two groups of data are shown in Tables 2-6.

Data shown in Table 2 clearly illustrate the case of independent variables in the model. There are three independent variables in the model: the type of roadway $\left(X_{1}\right)$, the accessible section area of the roadway $\left(X_{2}\right)$, and the inclination of the roadway $\left(X_{3}\right)$. The average wind velocity of the roadway $\left(X_{4}\right)$ was removed. The criterion of "enter" and "out" is shown in Table 2 , and the significance probability of the partial interpretation of the variance of the variables in the "enter" and "out" categories has a significance level of 0.05 and 0.1 , respectively, so that the probability of significant deviation from the statistical value of the partial interpretation is less than 0.05 to add more variables into the equation and greater than 0.1 to remove variables from the equation. Thus, the variables are prevented from being in the "enter" and "out" equation and got into an infinite loop.

Data shown in Table 3 summarize part of the linear regression model. The correlation coefficient $R$, the fitting coefficient of the regression models, the fitting coefficient 
TABLE 5: Excluded variables ${ }^{a}$.

\begin{tabular}{ccccccccccccc}
\hline \multirow{2}{*}{ Model } & \multicolumn{2}{c}{ Beta In } & \multicolumn{2}{c}{$\mathrm{t}$} & \multicolumn{2}{c}{ Sig. } & \multicolumn{2}{c}{ Partial Correlation } & \multicolumn{2}{c}{ Collinearity Statistics } \\
& & & & & & & \\
& Dip $\leqslant 0$ & Dip $\geqslant 0$ & Dip $\leqslant 0$ & Dip $\geqslant 0$ & Dip $\leqslant 0$ & Dip $\geqslant 0$ & Dip $\leqslant 0$ & Dip $\geqslant 0$ & Dip $\leqslant 0$ & Dip $\geqslant 0$ \\
\hline Roadway type & $-0.103^{\mathrm{b}}$ & $-0.168^{\mathrm{b}}$ & -1.183 & -1.534 & 0.247 & -0.274 & -0.222 & -0.274 & 0.947 & 0.660 \\
1 Roadway section area & $0.225^{\mathrm{b}}$ & $0.242^{\mathrm{b}}$ & 2.998 & 2.982 & 0.006 & 0.484 & 0.500 & 0.484 & 1.000 & 0.987 \\
Average wind velocity & $-0.013^{\mathrm{b}}$ & $0.178^{\mathrm{b}}$ & -0.154 & 2.069 & 0.879 & 0.359 & -0.030 & 0.359 & 1.000 & 0.997 \\
2 Roadway type & $-0.183^{\mathrm{c}}$ & $-0.236^{\mathrm{c}}$ & -2.482 & -2.542 & 0.020 & -0.433 & -0.438 & -0.433 & 0.871 & 0.634 \\
Average wind velocity & $-0.001^{\mathrm{c}}$ & $0.154^{\mathrm{c}}$ & -0.007 & 1.985 & 0.994 & 0.351 & -0.001 & 0.351 & 0.997 & 0.985 \\
3 Average wind velocity & $0.29^{\mathrm{d}}$ & $0.144^{\mathrm{d}}$ & 0.441 & 2.038 & 0.685 & 0.365 & 0.082 & 0.365 & 0.968 & 0.983 \\
\hline
\end{tabular}

a. Dependent variable: the miner escape velocity

b. Predictors in the model: (constant) the inclination of the roadway.

c. Predictors in the model: (constant) the inclination of the roadway and the accessible section area of the roadway.

d. Predictors in the model: (constant) the inclination of the roadway, the accessible section area of the roadway, and the type of roadway.

TABLE 6: Coefficients. ${ }^{\mathrm{a}}$

\begin{tabular}{|c|c|c|c|c|c|c|c|c|c|c|c|}
\hline \multirow{3}{*}{\multicolumn{2}{|c|}{ Model }} & \multicolumn{4}{|c|}{ Unstandardized Coefficients } & \multirow{2}{*}{\multicolumn{2}{|c|}{$\begin{array}{c}\text { Standardized Coefficients } \\
\text { Beta }\end{array}$}} & \multirow{2}{*}{\multicolumn{2}{|c|}{$\mathrm{t}$}} & \multirow{2}{*}{\multicolumn{2}{|c|}{ Sig. }} \\
\hline & & \multicolumn{2}{|c|}{ B } & \multicolumn{2}{|c|}{ Std. Error } & & & & & & \\
\hline & & Dip $\leqslant 0$ & Dip $\geqslant 0$ & Dip $\leqslant 0$ & Dip $\geqslant 0$ & Dip $\leqslant 0$ & Dip $\geqslant 0$ & Dip $\leqslant 0$ & Dip $\geqslant 0$ & Dip $\leqslant 0$ & Dip $\geqslant 0$ \\
\hline \multirow{3}{*}{1} & (Constant) & 2.703 & 2.871 & 0.098 & 0.103 & & & 27.546 & 27.843 & 0.000 & 0.000 \\
\hline & Roadway inclination & 0.051 & -0.051 & 0.005 & 0.005 & 0.893 & -0.868 & 10.513 & -9.568 & 0.000 & 0.000 \\
\hline & (Constant) & 2.337 & 2.405 & 0.149 & 0.181 & & & 15.637 & 13.279 & 0.000 & 0.000 \\
\hline \multirow[t]{3}{*}{2} & Roadway inclination & 0.051 & -0.049 & 0.004 & 0.005 & 0.898 & -0.840 & 11.975 & -10.337 & 0.000 & 0.000 \\
\hline & Roadway section area & 0.042 & 0.049 & 0.014 & 0.016 & 0.225 & 0.242 & 2.998 & 2.982 & 0.007 & 0.006 \\
\hline & (Constant) & 2.643 & 2.879 & 0.184 & 0.250 & & & 14.356 & 11.526 & 0.000 & 0.000 \\
\hline \multirow{3}{*}{3} & Roadway inclination & 0.054 & -0.057 & 0.004 & 0.005 & 0.941 & -0.973 & 13.279 & -10.677 & 0.000 & 0.000 \\
\hline & Roadway section area & 0.052 & 0.056 & 0.013 & 0.015 & 0.275 & 0.281 & 3.841 & 3.694 & 0.001 & 0.001 \\
\hline & Roadway type & -0.304 & -0.333 & 0.123 & 0.131 & -0.183 & -0.236 & -2.482 & -2.542 & 0.020 & 0.017 \\
\hline
\end{tabular}

a. Dependent variable.

after adjustment, and the standard errors are given for the variables if the independent variables of two multivariable regression models are $a, b$, and $c$, respectively, in Table 3 . The analysis results show that the correlation coefficient $R$, the fitting coefficient $R^{2}$, and the adjusted fitting coefficient are the largest, and the standard error is the smallest if the independent variables of the linear regression models are $c$. The fitted coefficients $A d j-R^{2}$ of the linear regression models were 0.863 and 0.830 , respectively, which were all higher than 0.8 . These results show that the regression models can explain $86.3 \%$ and $83 \%$ of the data variability, which indicates that the models have a high degree of fit.

The data shown in Table 4 are the results of variance analysis for the multivariable linear regression models. The sum of squares, the degrees of freedom, the mean square, $F$, and the significance of the variance of the multivariable regression models are given if the independent variables of the multivariable regression models are $b, c$, and $d$, respectively, in Table 4 . The sum of squares of the models increases with the process of stepwise regression. It can be seen that the variation has been explained more and more with the improvement of the models in the stepwise regression. In addition, the overall significance of the regression models is tested using the $F$ test, where the corresponding original hypothesis is that the regression model is not significant, and the alternative hypothesis is that the regression model is significant. As a result of the data in Table 4, the statistical significance probability Sig of each regression model is less than 0.05 , such that the original hypothesis should be rejected, the regression model passes the $\mathrm{F}$ test, and the regression effect is considered to be significant.

Data shown in Table 5 are the exclusion variables for the multivariable regression models. The table includes the input beta, the $t$ test value, the significance, the partial correlation row, and the collinearity statistical allowance for different independent variables of two multiple regression models. As seen from the data in Table 5 , the absolute values of the significance of the multivariable regression models are greater than 0.05 and the regression models are not significant and do not pass the $t$ test if the independent variables include the average wind velocity of the roadway.

The data in Table 6 show the coefficients of the multiple regression models. The parameter estimation and the related $t$ test are given by the regression models. From the $t$ statistic of this section, the significance of each set of correlation coefficients in the regression model was less than 0.05; therefore the original hypothesis should be rejected and the regression coefficient can be considered as significant, which 
means that $X_{1}, X_{2}$, and $X_{3}$ have significant influence on $Y_{1}$ and $Y_{2}$. In addition, the order of each variable entering into the models is the inclination of the roadway, the accessible section area of the roadway, and the type of roadway in the process of stepwise regression, which means that the independent variable of the inclination of the roadway has the greatest influence on the escape velocity, and the independent variable of the type of roadway has the least influence on the escape velocity. The independent variable of the average wind velocity was removed in the process of stepwise regression, and it has almost no influence on the miner escape velocity.

In conclusion, the multivariate regression models have the strongest significance and pass the goodness of fit test, the $t$ test, and the $F$ test if the independent variables of the regression models are the inclination of the roadway, the accessible section area of the roadway, and the type of roadway. Therefore, the inclination of the roadway, the accessible section area of the roadway, and the type of roadway are chosen as independent variables, and the miner escape velocity is taken as the dependent variable for the multivariable regression models. The constants and coefficients of the multivariable linear regression models are $\widehat{\beta}_{0}=2.643$, $\widehat{\beta}_{0}^{\prime}=2.879, \widehat{\beta}_{1}=0.054, \widehat{\beta}_{1}^{\prime}=-0.057, \widehat{\beta}_{2}=0.052, \widehat{\beta}_{2}^{\prime}=$ $0.056, \widehat{\beta}_{3}=-0.304$, and $\widehat{\beta}_{3}^{\prime}=-0.333$.

Therefore, the multivariable regression equations of the escape velocity during the experimental mine fire period are obtained by taking the miner escape velocity as the dependent variable and the inclination of the roadway, the accessible section area of the roadway, and the type of roadway as the independent variables:

$$
\begin{array}{ll}
Y_{1}=2.643+0.054 X_{1}+0.052 X_{2}-0.304 X_{3} & X_{1}<0 \\
Y_{2}=2.879-0.057 X_{1}+0.056 X_{2}-0.333 X_{3} & X_{1} \geqslant 0
\end{array}
$$

where $Y_{1}, Y_{2}$ are the miner escape velocity, in $\mathrm{m} / \mathrm{s}, X_{1}$ is the inclination of the roadway, in ${ }^{\circ}, X_{2}$ is the accessible section area of the roadway, in $\mathrm{m}^{2}$, and $X_{3}$ is the type of roadway, including track and trackless types.

3.3. Error Analysis. To verify the applicability of the mathematical models, error analysis was performed on the experimental data from group 62 to group 80 using the multiple regression equations. The escape velocities were predicted by the multiple regression equations of $Y_{1}$ and $Y_{2}$ and the experimental data of the inclination of the roadway, the accessible section area of the roadway, and the type of roadway. Thus, the errors of the mathematical models were obtained by comparing with the escape velocities of the miner measured in the experiment. The error analysis results are shown in Table 7. As seen from Table 7, the forecasting errors of the multiple regression equations of $Y_{1}$ and $Y_{2}$ are all less than $10 \%$, and the error values are all within the reasonable range. The analysis results are shown that the prediction results of the mathematical models are reliable. In conclusion, the multiple regression equations can be applied to the prediction of the miner escape velocity during mine fire period.

\section{Discussion}

At present, research on smoke concentration and temperature distribution in the roadway during mine fire period has been well developed both at home and abroad [21-25], but the research on the optimal escape route has been infrequent. The selection of the optimal escape route plays an important role for the escape of the miner during mine fire period; the optimal escape route is essentially the route that has the shortest time for the miner to escape and avoid the threat of high temperature smoke flow. The shortest escape time can be calculated by the length of the escape route and the escape velocity in each roadway of the escape route. The miner escape velocity in each roadway differs due to the complicated production environment and the various roadway conditions. Therefore, it is difficult to calculate the miner escape velocity during mine fire period accurately, which leads to the inability to choose the optimal escape route as the miner has not been received proper evacuation training and failed to escape fire threat area within valid time during mine fire period, eventually causing a large number of casualties of major accident.

To solve the problem above, we carried out the miner escape velocity in the underground coal mine and studied the influence of the inclination of the roadway, the accessible section area of the roadway, the average wind velocity of the roadway, and the type of roadway on the miner escape velocity during the mine fire period, obtained from the mathematical models of the escape velocity for miners in any roadway. The escape velocity can be calculated for miners in any roadway using the mathematical models, and the passage time for the miner to pass each route can be quickly obtained using the computer. In this way, the optimal escape route can be located quickly and accurately by comparing the passage time of each escape route and excluding the routes that include roadways threatened by high temperature smoke. In this paper, the miner escape velocity in different types of roadways was calculated with a quantitative method instead of a qualitative method, which is of great significance for solving the optimal escape route during mine fire periods. In addition, the mathematical models of the escape velocity can be applied not only to solve the optimal escape route during coal mine fires but also to solve the optimal escape route for metal mine fire accidents.

This study also has some limitations. A large amount of poisonous and harmful gases can be produced when a fire occurs in coal mine, but because the roadway polluted by smoke flow and the visibility of the roadway cannot be accurately observed, it leads to the decrease of the miner escape velocity in the process of evacuation [26]. In addition, due to the influence of the surrounding environment after a mine fire occurred, the miner may have nervous and anxious emotions, which will have a negative impact on the psychological and physical health of the miner, and the physiological indexes of the human body will change substantially [27]. Therefore, an escape experiment can be carried out in the ground test roadway in future research, and the influence of the smoke concentration and human physiological indexes on the escape velocity can be taken into 
TABLE 7: Error analysis of the mathematical models.

\begin{tabular}{|c|c|c|c|c|c|c|c|}
\hline \multirow{2}{*}{ No. } & \multirow{2}{*}{ roadway name } & \multirow{2}{*}{$\mathrm{Dip} /{ }^{\circ}$} & \multirow{2}{*}{$\begin{array}{l}\text { Escape velocity } \\
\mathrm{m} / \mathrm{s}\end{array}$} & \multicolumn{2}{|c|}{ Regression equation: $Y_{1}$} & \multicolumn{2}{|c|}{ Regression equation: $Y_{2}$} \\
\hline & & & & predicted value $\mathrm{m} / \mathrm{s}$ & Error value/\% & predicted value $\mathrm{m} / \mathrm{s}$ & Error value/\% \\
\hline 1 & $\begin{array}{c}+250-+450 \text { auxiliary } \\
\text { shaft slope }\end{array}$ & 27.5 & 1.64 & - & - & 1.78 & 8.66 \\
\hline 2 & $\begin{array}{l}+820 \text { fifth west cross } \\
\text { drift }\end{array}$ & 0 & 2.96 & 2.70 & 8.71 & 2.93 & 0.96 \\
\hline 3 & $\begin{array}{c}+820 \text { fifth west cross } \\
\text { drift }\end{array}$ & 0 & 2.79 & 2.70 & 3.15 & 2.93 & 5.07 \\
\hline 4 & $\begin{array}{l}+820 \text { roof road of } \\
\text { north cross drift }\end{array}$ & 0 & 2.82 & 2.72 & 3.61 & 2.95 & 4.57 \\
\hline 5 & $\begin{array}{l}+820 \text { roof road of } \\
\text { north cross drift }\end{array}$ & 0 & 2.76 & 2.72 & 1.51 & 2.95 & 6.84 \\
\hline 6 & $\begin{array}{l}+570 \text { seventh west } \\
\text { cross drift }\end{array}$ & 0 & 2.64 & 2.52 & 4.48 & 2.74 & 3.68 \\
\hline 7 & $\begin{array}{l}+570 \text { seventh west } \\
\text { cross drift }\end{array}$ & 0 & 2.58 & 2.52 & 2.26 & 2.74 & 6.09 \\
\hline 8 & $\begin{array}{l}+150 \text { down } \\
\text { crossheading of } \\
\text { second face }\end{array}$ & -16.1 & 1.85 & 1.84 & 0.93 & - & - \\
\hline 9 & $\begin{array}{l}+150 \text { down } \\
\text { crossheading of } \\
\text { second face }\end{array}$ & 16.1 & 2.16 & - & - & 2.02 & 6.30 \\
\hline 10 & $\begin{array}{l}+150 \text { up crossheading } \\
\text { of second face }\end{array}$ & -12.3 & 2.02 & 2.17 & 7.62 & - & - \\
\hline 11 & $\begin{array}{l}+150 \text { up crossheading } \\
\text { of second face }\end{array}$ & 12.3 & 2.25 & - & - & 2.38 & 5.86 \\
\hline 12 & $\begin{array}{l}+150 \text { east level } \\
\text { roadway }\end{array}$ & 0 & 2.88 & 2.76 & 4.30 & 2.99 & 3.81 \\
\hline 13 & $\begin{array}{l}+150 \text { east level } \\
\text { roadway }\end{array}$ & 0 & 2.82 & 2.76 & 2.26 & 2.99 & 6.02 \\
\hline 14 & $\begin{array}{l}+150 \text { mining section } \\
\text { east roadway }\end{array}$ & 0 & 2.64 & 2.55 & 3.55 & 2.76 & 4.68 \\
\hline 15 & $\begin{array}{l}+150 \text { mining section } \\
\text { east roadway }\end{array}$ & 0 & 2.67 & 2.55 & 4.64 & 2.76 & 4.64 \\
\hline 16 & $\begin{array}{l}+700 \text { second west } \\
\text { cross drift }\end{array}$ & 0 & 2.81 & 2.67 & 5.06 & 2.89 & 3.01 \\
\hline 17 & $\begin{array}{l}+700 \text { second west } \\
\text { cross drift }\end{array}$ & 0 & 2.73 & 2.67 & 2.28 & 2.89 & 6.03 \\
\hline 18 & $\begin{array}{c}+450 \text { haulage } \\
\text { roadway }\end{array}$ & 0 & 2.74 & 2.59 & 5.46 & 2.81 & 2.59 \\
\hline 19 & $\begin{array}{l}+450 \text { haulage } \\
\text { roadway }\end{array}$ & 0 & 2.62 & 2.59 & 1.13 & 2.81 & 7.29 \\
\hline
\end{tabular}

consideration to make the prediction model more accurate and reliable.

\section{Conclusions}

In this paper, we carried out a number of experiments in the $\mathrm{Mu}$ Chengjian Coal Mine to study the relationship between the miner escape velocity and the inclination of roadway, the accessible section area of the roadway, the type of roadway, and the average wind velocity of the roadway. In addition, we analyzed the influence of many factors on the escape of the miner during a mine fire period using a multivariable linear regression analysis. Finally, we analyzed the error of the mathematical models using the experimental data. The main conclusions are as follows:

(1) The results of the single factor analysis show that the miner escape velocity decreases gradually with an increase in the absolute value of the inclination. In addition, the escape velocity increases with an increase in the accessible section area of the roadway and increases with an increase in the average wind velocity of the roadway.

(2) The results of the multiple regression analysis show that the multivariable regression models have the strongest significance if the independent variable is the inclination of the roadway, the access section area of the roadway, and the type of roadway and if the contribution rate of each variable to 
the miner escape velocity from large to small is the inclination of the roadway, the accessible section area of the roadway, and the type of roadway.

(3) Two mathematical models are obtained through a multiple regression analysis of the experimental data. These models took the miner escape velocity as the dependent variable and took the inclination of the roadway, the accessible section area of the roadway, and the type of roadway as independent variables. Then, the prediction errors of the multiple regression equations were analyzed using the experimental data, and the results show that the predicted results are close to the measured results, with prediction errors that are lower than $10 \%$. In summary, we concluded that the mathematical models can be used to predict the miner escape velocity during mine fire periods.

\section{Conflicts of Interest}

The authors declare that there are on conflicts of interest related to this paper.

\section{Acknowledgments}

This work is supported by the Support Projects in the National Science \& Technology Pillar Program (2015BAK38B01).

\section{References}

[1] J. Huang, J. Bruining, and K.-H. A. A. Wolf, "Modeling of gas flow and temperature fields in underground coal fires," Fire Safety Journal, vol. 36, no. 5, pp. 477-489, 2001.

[2] I. E. Perera and C. D. Litton, "Impact of Air Velocity on the Detection of Fires in Conveyor Belt Haulageways," Fire Technology, vol. 48, no. 2, pp. 405-418, 2012.

[3] K. Wang, S. Jiang, X. Ma et al., "Numerical simulation and application study on a remote emergency rescue system during a belt fire in coal mines," Natural Hazards, vol. 84, no. 2, pp. 1463-1485, 2016.

[4] J. I. Jingwei, J. Zhang, J. Chen, and W. U. Shuang, "Computer simulation of evacuation in underground coal mines," in Proceedings of the International Journal of Mining Science and Technology(fb, pp. 677-681, 2010.

[5] S. E. Jalali and M. Noroozi, "Determination of the optimal escape routes of underground mine networks in emergency cases," Safety Science, vol. 47, no. 8, pp. 1077-1082, 2009.

[6] K. Wang, S. Jiang, X. Ma et al., "Information fusion of plume control and personnel escape during the emergency rescue of external-caused fire in a coal mine," Process Safety and Environmental Protection, vol. 103, pp. 46-59, 2016.

[7] Y. Yang, J. Deng, C.-C. Xie, and Y.-T. Jiang, "Design and implementation of fire safety evacuation simulation software based on cellular automata model," in Proceedings of the 2013 International Conference on Performance-Based Fire and Fire Protection Engineering, ICPFFPE 2013, pp. 364-371, chn, November 2013.

[8] G. Yan and D. Feng, "Escape-route planning of underground coal mine based on improved ant algorithm," Mathematical Problems in Engineering, vol. 2013, 2013.

[9] R. Gao, Z. Jiang, F. Dong et al., "Mathematical model and algorithm of a dynamic optimum rescue route during mine fire time based on MapObject," Beijing Keji Daxue Xuebao/Journal of University of Science and Technology Beijing, vol. 30, no. 7, pp. 705-755, 2008.

[10] L. L. Bai, “The Simulation Research of Person's Evacuation Along Underground Tunnel's Fire Based on Cellular Automaton," Science Technology Information, 2010.

[11] Y. U. Dan-Dan, "Research of New Method of Computer Simulation on People Escaping Along Underground Tunnels System Based on Cellular Automate," Science Technology Information, 2009.

[12] C. P. Li, Z. G. Cao, Z. X. Li, L. Hu, and D. Y. Hou, "3D simulation modeling techniques of fire fume spread process for underground mines," Journal of China Coal Society, vol. 38, no. 2, pp. 257-263, 2013.

[13] Z.-X. Li, Y.-D. Wang, and L. Li, "3D simulation of disaster process in mine ventilation system during fire period," Meitan Xuebao/Journal of the China Coal Society, vol. 40, no. 1, pp. 115121, 2015.

[14] Z. Fubao, Characteristics of roadway network fire and computer Simulation, China University of Mining and Technology Press, Xuzhou, China, 2007.

[15] D. Wang, Decision support system of Disaster relief for Mine fire disaster, Coal Industry Press, Beijing, China, 1996.

[16] J. H. Wang, Y. J. Zhang, and L. I. Yu-Ping, "Mathematical modeling and algorithm's research of optimal hedge underground route's GIS network analysis," Journal of China Coal Society, no. (S2), pp. 411-415, 2014.

[17] S. Zhang, Z. Wu, R. Zhang, and J. Kang, "Dynamic numerical simulation of coal mine fire for escape capsule installation," Safety Science, vol. 50, no. 4, pp. 600-606, 2012.

[18] C.-K. Ing and T. L. Lai, "A stepwise regression method and consistent model selection for high-dimensional sparse linear models," Statistica Sinica, vol. 21, no. 4, pp. 1473-1513, 2011.

[19] N.-Z. Sun, S.-L. Yang, and W. W.-G. Yeh, "A proposed stepwise regression method for model structure identification," Water Resources Research, vol. 34, no. 10, pp. 2561-2572, 1998.

[20] W. Li, Application of multivariate statistical analysis, Peking University Press, Beijing, China, 2015.

[21] C. G. Fan, X. Y. Li, Y. Mu, F. Y. Guo, and J. Ji, "Smoke movement characteristics under stack effect in a mine laneway fire," Applied Thermal Engineering, vol. 110, pp. 70-79, 2017.

[22] S. R. Lee and H. S. Ryou, "A numerical study on smoke movement in longitudinal ventilation tunnel fires for different aspect ratio," Building and Environment, vol. 41, no. 6, pp. 719$725,2006$.

[23] C. D. Litton and I. E. Perera, "Evaluation of criteria for the detection of fires in underground conveyor belt haulageways," Fire Safety Journal, vol. 51, pp. 110-119, 2012.

[24] C. Liu, M. Zhong, C. Shi, P. Zhang, and X. Tian, “Temperature profile of fire-induced smoke in node area of a full-scale mine shaft tunnel under natural ventilation," Applied Thermal Engineering, vol. 110, pp. 382-389, 2017.

[25] S. Wang, X. Li, and D. Wang, "Mining-induced void distribution and application in the hydro-thermal investigation and control of an underground coal fire: A case study," Process Safety and Environmental Protection, vol. 102, pp. 734-756, 2016.

[26] O. Vauquelin and O. Mégret, "Smoke extraction experiments in case of fire in a tunnel," Fire Safety Journal, vol. 37, no. 5, pp. 525-533, 2002.

[27] B. Nie, X. Huang, X. Sun, and A. Li, "Experimental study on physiological changes of people trapped in coal mine accidents," Safety Science, vol. 88, pp. 33-43, 2016. 


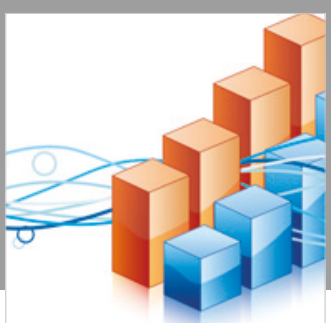

Advances in

Operations Research

\section{-n-m}
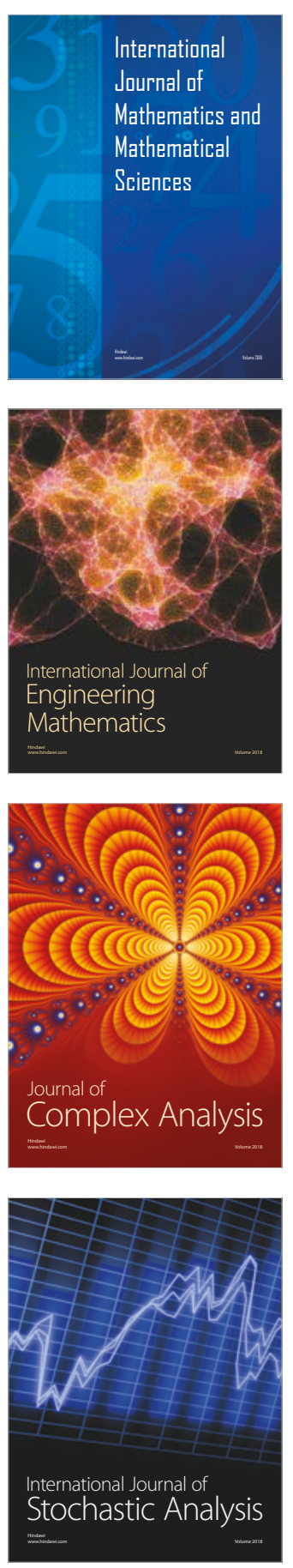
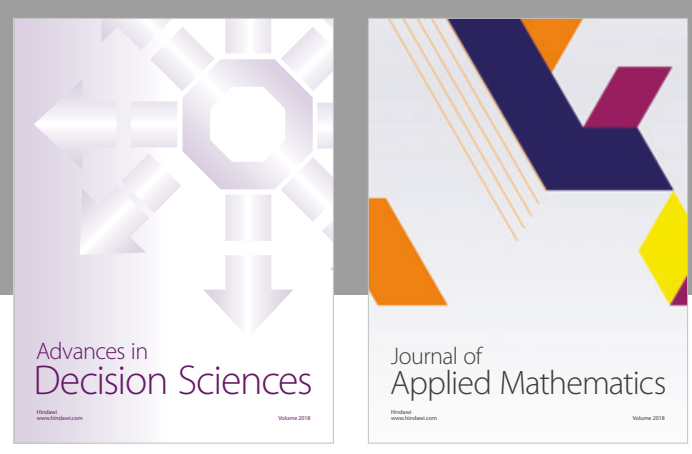

Journal of

Applied Mathematics
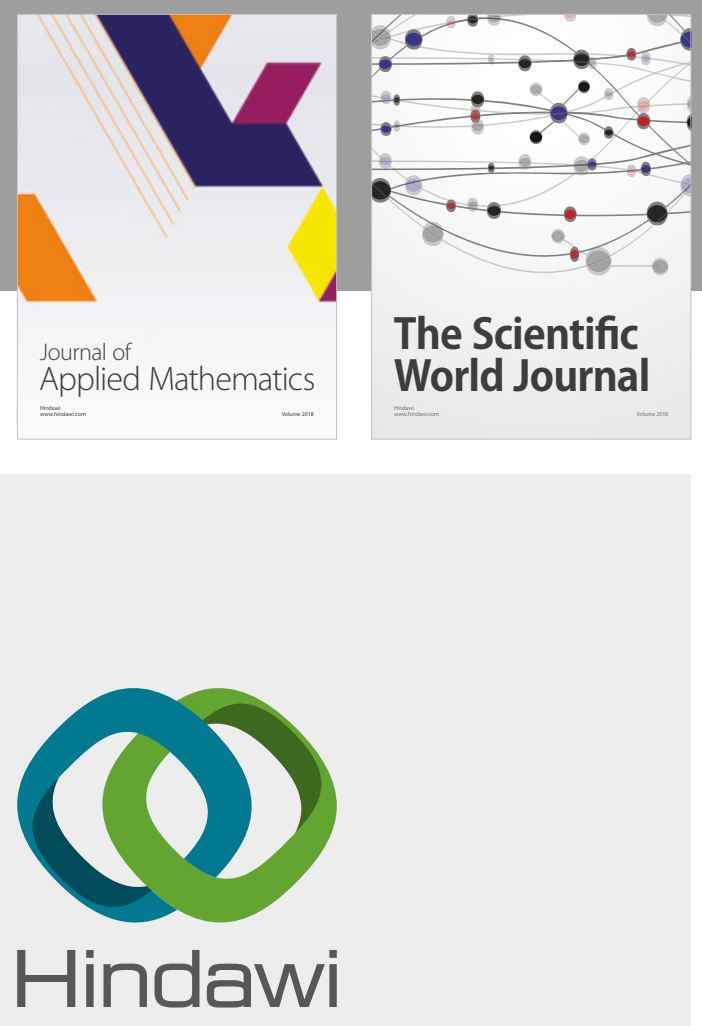

Submit your manuscripts at

www.hindawi.com

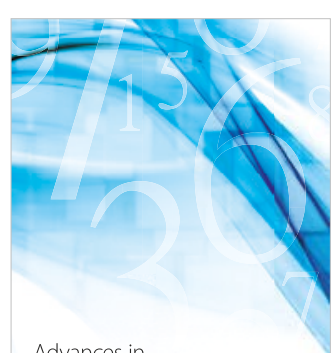

Advances in
Numerical Analysis
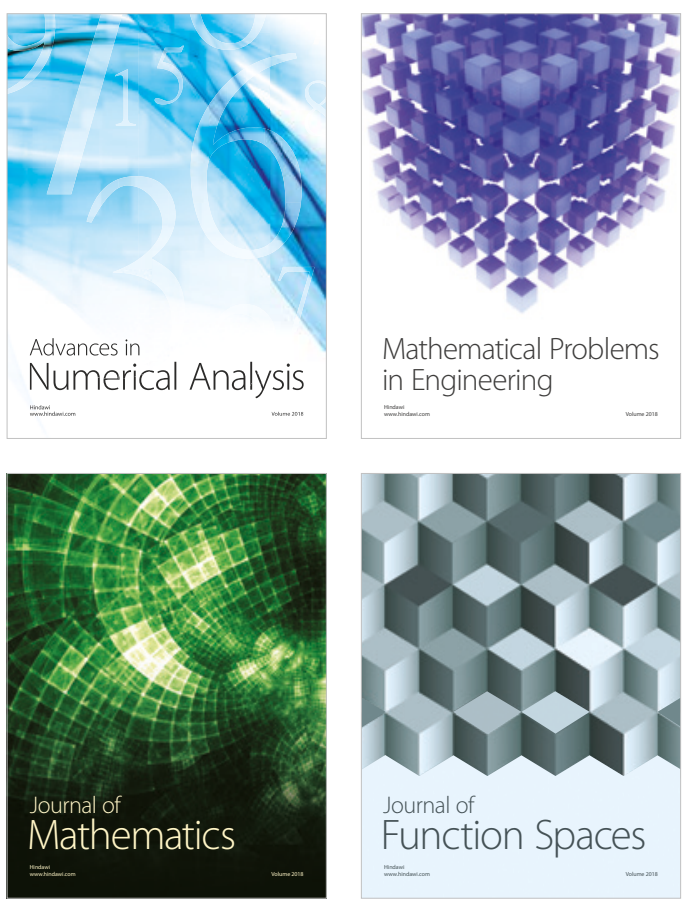

Mathematical Problems in Engineering

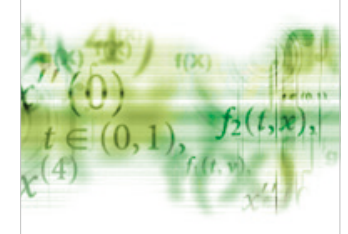

International Journal of

Differential Equations

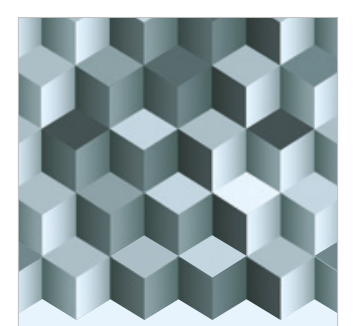

Journal of

Function Spaces

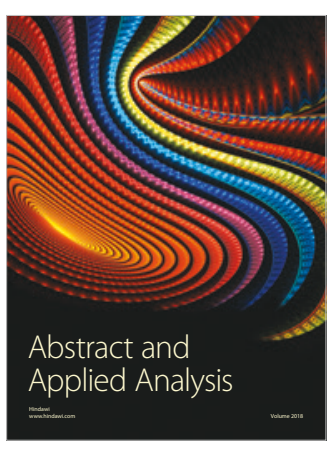

The Scientific

World Journal

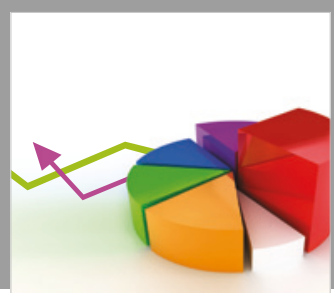

Journal of

Probability and Statistics
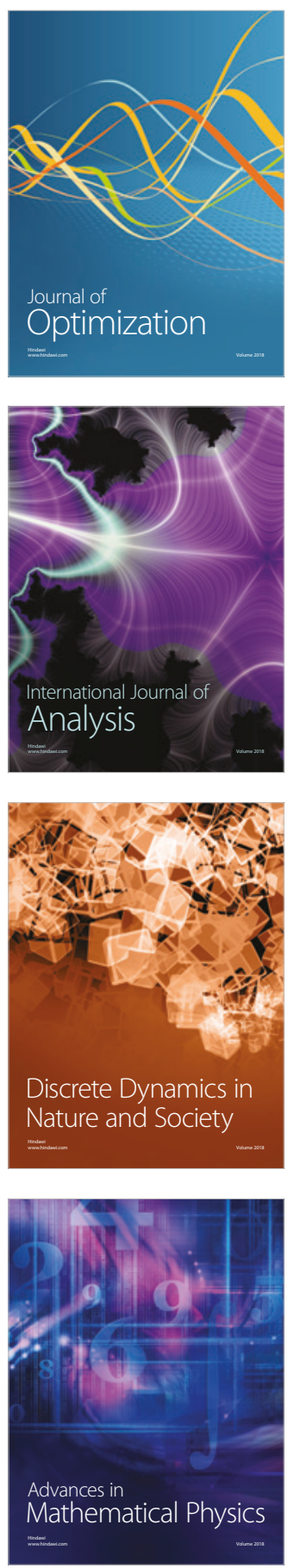